\title{
The Relationship between Self-esteem and Social Media Engagement of College Students: The Mediation Role of Social Intelligence
}

\author{
Ulwiyyah and Yan Wu \\ Northeast Normal University, China
}

\begin{abstract}
This study investigates the relationship between self-esteem and social media engagement of college students in Indonesia through mediator role of social intelligence. 157 undergraduate students participated (75 male, 81 female) completing the questionnaires. Scales of The Rosenberg Self-Esteem Scale (RESE), The Social Media Engagement Questionnaire (SMEQ), and The Tromso Social Intelligence Scale (TSIS) were translated into Indonesian language. The results indicated that there was no direct relationship between self-esteem and social media engagement, however there was indirect relationship of self-esteem on social media engagement through social intelligence. Age also moderated social intelligence and there was interaction effect between gender and social intelligence.
\end{abstract}

Keywords: social intelligence, self-esteem, social media engagement 


\section{SOCIAL SCIENCE, HUMANITIES \& EDUCATION}

\section{6 - 8 MARCH 2020}

BUDAPEST, HUNGARY

\section{Introduction}

Self-esteem in sufficient level is a strong indicator of individual's general well-being and level of social context adjustment and protects toward psycho-social risks (Forzi \& Not, 2003). On the other hand, social media has become the primary mode of sharing and communicating information and becomes an integral part of many people. This media provides easy access to real-time information about activities, academics, recreation sector, events, and conversations that occur on various social networks that make social media more inseparable (Hahn \& Kim, 2014). Users are also separated from real-life social support which plays significant role of engagement (Lin, You, Ren, Wu, Hu, Yen, \& Zhang, 2017; Wang \& Wang, 2013; Wegmann $\&$ Brand, 2016). Whereas, social awareness which can be found broadly in real interaction could predict what might occur in social interactions as well as recognize their effects on those interactions. Better social interaction brings perceive of confident and accepted.

Social intelligence is composed of the ability to process social information, social skills, and social awareness (Silvera, Martinussen, \& Dahl,, 2001). Therefore, it could produce appropriate behavior aimed at achieving the desired social goals. Social intelligence is associated with increasing of social perception and behavioral flexibility (Zaccaro, Gilbert, Thor, \& Mumford, 1991). It consists 3 dimensions, social information processing which relates to the cognitive aspect of empathy, social skills which capture capacity of an individual to engage in social behavior that suits the situation with others, and social awareness which involves one's ability to remain in synch with, and not be surprised by what happens in social situations (Delič, Novak, Kovačič, \& Avsec, 2011).

Rhodewalt and Vohs (2005) argue that social intelligence is involved in the way individuals view their self-esteem, describe their self-confidence, understand threats and choose strategies to overcome challenges. Socially intelligent individuals are very capable of solving problems of daily life and coping with socially threatening events using appropriate strategies. Regarding gender differences, female is reported to have more social processing ability (Gini \& Iotti, 2008; Mejis, Cillessen, Scholte, Segers \& Spijkerman, 2008).

Self-esteem correlates strongly and positively with the behavioral and emotional component of Social Intelligence. Socially intelligent individuals with higher levels of self-esteem are better able to analyze the social behavior of others, to recognize their motives and cognitive abilities and produce appropriate behaviors for social contexts (Cantor \& Kihlstrom, 1987).

Self-esteem is defined as a person's attitude towards himself and reflects how a person evaluates his self-concept (Aydın \& Sar, 2011). Self-esteem is conceptualized as having two dimensions, self-efficacy and self-worth. The efficacy dimension describes the perception of one's own social competence. The worth dimension refers to the degree that individuals feel they are a person of value (Dong, Koper, \& Collaço, 2008). 


\section{SOCIAL SCIENCE, HUMANITIES \& EDUCATION}

\section{6 - 8 MARCH 2020}

BUDAPEST, HUNGARY

Prior study revealed gap of gender on self-esteem that male have higher self-esteem than female (Orth, Trzesniewski, \& Robins, 2010; Robins, Trzesniewski, Tracy, Gosling, \& Potter, 2002; Shaw, Liang, \& Krause, 2010; Trzesniewski, Donnellan, \& Robins, 2003; Twenge \& Campbell, 2001; Mellor, Fuller, McCabe, \& Ricciardelli, 2010; Maltese, Alesi, \& Alù, 2012; Bleidorn, Denissen, Gebauer, Arslan, Rentfrow, \& Potter, 2016). A study revealed that students' self-esteem has a significant impact on the way they engage in activities, face challenges, and interact with others.

Previous studies explored on the motives of social media engagement which were to avoid negative emotional states such as loneliness, (Burke, Marlow, \& Lento, 2010), less satisfaction of life, more depressed moods and boredom (Meerkerk, van den Eijnden, Franken, \& Garretsen, 2010) as well as correlation with psychological conditions such as anxiety, avoidance, and attachment (Kim \& Koh, 2018), self-esteem (Faraon \& Kaipainen, 2014; Wartberg, Kriston, Bröning, Kegel, \& Thomasius, 2017, Kim \& Koh, 2018, Kim \& Davis, 2009; Armstrong, Phillips, \& Saling, 2000; Niemz, Griffiths, \& Banyard, 2005; Wiederhold, 2016), well-being (Verduyn, Ybarra, Re sibois, Jonides, \& Kross, 2017), and social support (Lin, You, Ren, Wu, Hu, Yen, \& Zhang 2017, Wang \& Wang, 2013).

Demographic factors such as gender also investigated to see level of social media engagement which has no significant different, span of development in which young people are more likely to embrace or involve deeper social media as well as higher levels of education are also more likely to engage more deeply with continuity below, college followed by high school level and lower (Xu \& Mocarski, 2014).

Recently, as social media becomes a trend of communication mode, number of user is becoming huge. In Indonesia, according to Statista Research Department (2019) shows the number of social network users by 2019 is 86.5 million. In 2023, it is estimated that will increase rapidly to 103.1 million, up from 74.2 million in 2016. Thus, this study wants to fill the gap if the social media engagement of people could be mediated by social intelligence. Specifically, this study would investigate the relationship between self-esteem and social media engagement through mediation role of social intelligence among college students that was found to more engage than other level of education (Perrin, 2015; Xu \& Mocarski, 2014). The study found that $90 \%$ of active user are young adults at age 18-29 (Cohen, Newton-John, \& Slater, 2018). In the final, this study would see the moderation role of age difference among college students on the relationship between social intelligence and self-esteem in consideration of previous studies that indicated age played significant role on social intelligence and self-esteem.

This study hypothesized that there would be a positive relationship between self-esteem and social media engagement; social intelligence would mediate the role of self-esteem on social media engagement; age of college students would moderate the relationship between social intelligence and social media engagement. 


\begin{abstract}
Method
Participants

Online survey was administered in Walisongo State Islamic University, Indonesia. Online survey was distributed to some student representatives to forward the questionnaire to their peers in undergraduate level. Total number of respondents completed the questionnaire was 157,75 of them were male, and 81 were female ranging in age from 17 to 24 years $(M=1.923$, $S D=0.791)$. 72 students were first year students, 27 were second year students, 37 were third year, and 20 were fourth year and above.
\end{abstract}

\title{
Instruments
}

Researchers used three scales to measure self-esteem, social media engagement, and social intelligence. The scales were translated by lecturer of English language and psychologist into Indonesian language. The scales include demographic information about gender, age and year of study.

\section{The Rosenberg Self-Esteem Scale (RESE)}

The RESE (Rosenberg, 1965) comprises of 9 items originally consisting 10 items. 1 item was omitted due to invalid to measure. This scale evaluates global self-esteem. It was classified on a 4 -point scale, ranging from $1=$ strongly disagree to $4=$ strongly agree, and the internal consistency coefficients were .734 .

The Social Media Engagement Questionnaire (SMEQ)

SMEQ adopting from Przybylski, Murayama, DeHann, \& Gladwell (2013) was used. The scale consists 5 items with the response scale provided in a 8 point likert scale from 0 not one day to 7 every day. The reliability of scale was .826 .

\section{The Tromso Social Intelligence Scale (TSIS)}

TSIS (Silvera, Martinussen and Dahl, 2001) consists 21 items with three independent subscales related to Social information Processing, (SP) (7 items), Social Skills, (SS) (7 items) and Social Awareness, (SA) (7 items). The degree of affirmation was rated in a 5 point scale from strongly disagree to 5 strongly agree. The reliability of subscale of SP was .809.

\section{Statistical Analysis}

IBM Statistic version 23 was used to analyze the descriptive and correlational analyses. Pearson correlation was used to find the relationship among the variables. Process v3.4 for SPSS was used for further analysis to examine the mediation, respectively. 


\section{SOCIAL SCIENCE, HUMANITIES \& EDUCATION}

\section{6 - 8 MARCH 2020}

BUDAPEST, HUNGARY

\section{Results}

\section{Compare Means analysis}

Independent sample t-test to see the differences in students' self-esteem, social media engagement, and social intelligence based on gender, was used. The result showed there was no significant different between male and female on self-esteem $t(154)=1.031, p=.034$, on social media engagement, $t(154)=-1.454, p=.148$, and on social intelligence, $t(154)=-$ $1.885, p=.061$.

However, the mean score indicated that male scored higher on self-esteem $(M=23.33, S D=$ 4.338) than female $(M=22.65, S D=3.883)$. Opposite score was found that females scored higher on social media engagement $(M=15.44, S D=10.109)$ than male $(M=13.11, S D=$ 9.952) aw sell as social intelligence $(M=67.42, S D=9.770)$ for female and $(M=64.44, S D=$ 9.965) for male.

For age and year of study of students, researchers analyzed using ANOVA. The finding showed there were no significant difference of age on social media engagement, $F(3,152)=.604, p$ $=.613$ and on social intelligence, $F(3,152)=.662, p=.577$. However, age was found to be significant difference at $F(3,152)=2.728, p=.046$. The LSD post hoc test revealed selfesteem was statistically different in the age 21-22 years $(M=19.40, S D=5.550, p=.010)$. There was no statistically significant different among other groups. While year of study showed there were no significant difference of year of study on self-esteem $F(23,132)=1.466, p=.093$, on social media engagement, $F(3,152)=2.728, p=.046$, and on social intelligence, $F(40,115)$ $=1.348, p=.112$.

Table 1

Descriptive Statistics

\begin{tabular}{llll}
\hline Variables & Mean & SD & Range \\
\hline SE & 22.98 & 4.109 & 25 \\
SME & 14.32 & 10.070 & 35 \\
SI & 65.99 & 9.945 & 68 \\
\hline
\end{tabular}

\section{Correlations among variables}

In order to find the relationship among self-esteem, social media engagement, and social intelligence, researchers performed correlation analysis. The results indicated that self-esteem was found to be strongly correlated with social intelligence $r(156)=.272, p=.001$. Nevertheless, self-esteem did not correlate with self-esteem $r(156)=.073, p=.363$. Social media engagement and social intelligence were significantly and positively correlated, $r(156)$ $=.175, p=.029$. 


\section{SOCIAL SCIENCE, HUMANITIES \& EDUCATION}

6 - 8 MARCH 2020

BUDAPEST, HUNGARY

Table 2

Correlation among Variables

\begin{tabular}{llll}
\hline Variables & 1 & 2 & 3 \\
\hline 1. SI & - & & \\
2. SE & $.272 * *$ & - & \\
3. SME & $.175^{*}$ & .073 & - \\
\hline
\end{tabular}

$* p<.05$.

$* * p<.01$.

\section{Moderated Mediation Analysis}

The result showed that self-esteem was positively associated with social intelligence $b=.66$, $S E=.19, p=.00,95 \% \mathrm{CI}[.29,1.02]$ which in turn predicted social media engagement, $b=.17$, $S E=.08, p=.04,95 \%$ CI $[.00, .33]$. The direct and total effect indicated there were no significant result, $b=.06, S E=.20, p=.73,95 \%$ CI [-.33, .47]; $b=.18, S E=.20, p=.36,95 \%$ CI $[-.20, .57]$. However, the indirect effect of self-esteem on social media engagement through social intelligence was significant, $b=.11,95 \%$ Boot CI [-.02, .27].

The index of moderation indicated that age positively predicted social intelligence $b=-.11, S E$ $=5.20, p=.03,95 \% \mathrm{CI}[-.21,-.76]$. The interaction between social intelligence and self-esteem also showed significant, $b=.47, S E=.22, p=.03,95 \%$ CI $[-1.15, .05]$.

Overall, the model indicated that self-esteem did not directly predicted social media engagement, but the relationship between self-esteem and social media engagement was indirectly mediated by social intelligence. Additionally, the result revealed that when the selfesteem and year increased, students reported higher level of social intelligence. It is in turn associated with higher level of social media engagement. Furthermore, the indirect effect of self-esteem and social media engagement through social intelligence was moderated by age of students.

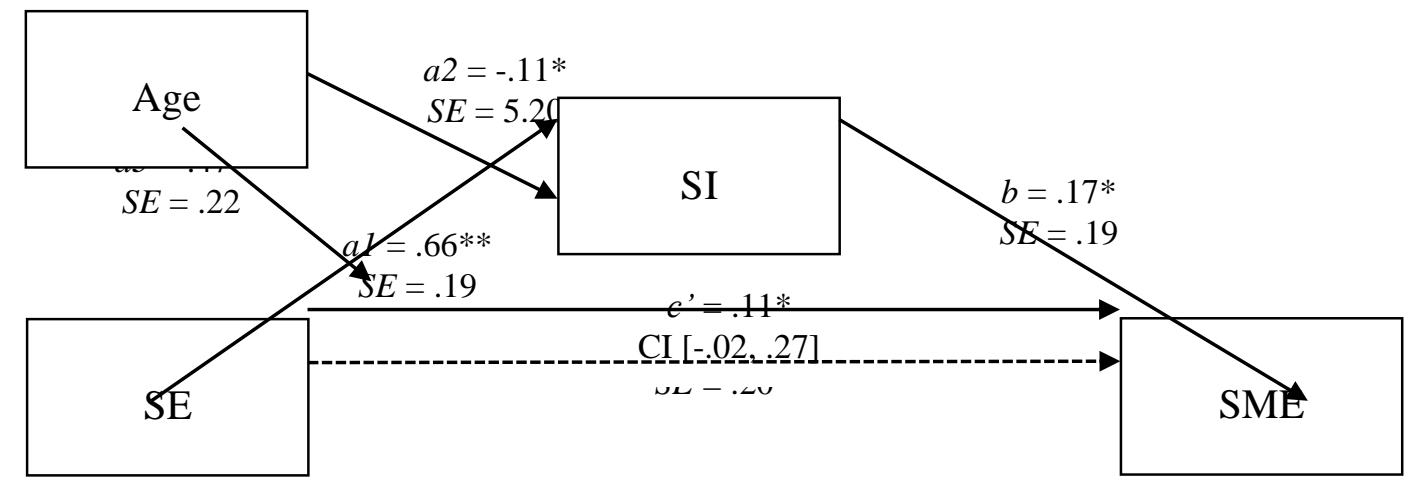

Note. $* p<.05 * * \mathrm{p}<.01$ 
Figure. 1. Moderated mediation model of Social Intelligence.

Note. Dotted represents the role of self-esteem on social media engagement when social intelligence is not included as a mediator.

\section{Discussion}

This study confirms that there are no significant differences regarding gender in social intelligence, self-esteem, and social media engagement among students. This finding contradicts most of the researches that have been done (Gini \& Iotti, 2008; Mejis et al., 2008; Orth, et al. 2010; Robins et al., 2002; Shaw, et al., 2010; Trzesniewski, et al., 2003; Twenge \& Campbell, 2001; Bleidorn, et al., 2016). This indicates that social intelligence can be fostered and trained by social involvement of each individual because it is a set of practical skills to interact successfully in any setting. Meanwhile self-esteem is shaped by the cultures that Asian countries found to have small difference regarding to gender compared to western countries. Furthermore, it appears to exert a stronger relationship. In contrary, social media engagement finding emphasizes previous findings (Perrin, 2015; Xu \& Mocarski, 2014). It becomes an indication that social media has plague people regardless gender. Especially students who consider social media as an approach in the learning process.

The age and year of study also does not contribute significantly to social intelligence, selfesteem, and social media engagement. It might due to the discrimination of the variables as well as the sample size which are small.

The main finding, revealed that self-esteem positively correlated with social intelligence which is consistent with prior findings (Rhodewalt \& Vohs, 2005; Maltese et al., 2012). The positive self-worth plays a major role in the overall well-being and degree of adaptation to the social context of the person. Socially intelligent individuals with higher level of self-esteem are more capable of recognizing other people's social behavior, identifying their motives and cognitive and generating appropriate behavior for the social context. As a result, they use less defensive strategies because they are more capable to cope with daily life problems and to find adequate resolutions of conflict. Furthermore, social intelligence shows to be correlated with social media engagement which means socially intelligent students engage more in social media activity. Social intelligence could give the desire to engage in social activities as well as could be acquired in getting along with social interaction.

There is no research which has examined the mediation role of social media engagement in the relationship between social intelligence and self-esteem. The present study does not find direct relationship between self-esteem and social media engagement through social intelligence. Although previous studies found negative relationship between self-esteem and social media 


\section{SOCIAL SCIENCE, HUMANITIES \& EDUCATION}

6 - 8 MARCH 2020

BUDAPEST, HUNGARY

and internet engagement (Faraon \& Kaipainen, 2014; Wartberg, Kriston, Bröning, Kegel, \& Thomasius, 2017, Kim \& Koh, 2018, Kim \& Davis, 2009; Armstrong, Phillips, \& Saling, 2000; Niemz, Griffiths, \& Banyard, 2005; Wiederhold, 2016). Significance of this study remains in indirect relationship which exists between them. This result emphasizes the importance of social intelligence for students in social interaction through current widely used modes. It reveals that self-esteem is not enough to increase level of engagement in social media interaction, students should activate social intelligence as well. Likewise, this study found age moderate social intelligence, and there was interaction effect between self-esteem and social intelligence moderated by gender.

The researchers offer a couple of suggestion because this study contains some limitations. The study adapts cross-sectional study which makes difficult to explain the causal relationship between social intelligence, self-esteem, and social media engagement. Future studies might undertake longitudinal study to explore influential role in the relationship.

This study does not find significant effect of demographic factors on all variables. Future research might consider to conduct in larger sample to see the effect of demographic factors and generalize the prior findings.

We found significant result that self-esteem and social intelligence could predict social media engagement with small effect size on the social intelligence predicting social media engagement and indirect effect of self-esteem and social media engagement. Thus, to replicate the study with different samples and to investigate the consistency of the finding when using different measure would be important. Further research must be considered hereby to obtain valid results. Future research also considers educational outcomes to assess the relationship between social media engagement and psychological conditions.

In addition to the limitations, the findings have a theoretical implication through the wellbeing theory which states that an individual's experience is entangled with material and relational dimensions of welfare and wellbeing (White \& Blackmore, 2015). An individual has less reflection on whether or not other people realize his/ her hope than a matter of learning how to live within boundaries. Thus, wellbeing can be fostered in relation. As well as social media engagement of college students which answers to current phenomenon as social media is kind of mode for communicating. Communicating through social media engages ability such as communicating through offline and affects on self-worth evaluation as well.Future studies are necessary to demonstrate mediation role of social intelligence as a mediation role through different relationship in different methodologies and sample as it becomes strong predictor into other variables. 


\section{References}

Armstrong, L., Phillips, J. G. \& Saling, L. L. (2000). Potential Determinants of Heavier Internet usage. International Journal of Human - Computer Studies, 53, 537-550.

Aydin, B., \& Sarı, S. V. (2011). Internet addiction among adolescents: the role of self-esteem. Procedia Social and Behavioral Sciences, 3500-3505.

Bleidorn, W., Denissen, J. J. A., Gebauer, J. E., Arslan, R. C., Rentfrow, P. J., \& Potter, J. (2016). Age and Gender Differences in Self-Esteem-A Cross-Cultural Window. Journal of Personality and Social Psychology. 111, 3. 396-410. http://dx.doi.org/10.1037/pspp0000078.

Burke, M., Marlow, C. and Lento, T. (2010). Social Network Activity and Social Well-Being. Proceeding of the 28th ACM Conference on Human Factors in Computing Systems, Atlanta, 10-15 April 2010, 1909-1912.

Cantor, N., and Kihlstrom, J. F. (1987). Personality and social intelligence. Englewood Cliffs, New Jersey: Prentice Hall.

Cohen, R., Newton-John, T., \& Slater, A. (2018). 'Selfie'-objectification: The role of selfies in self-objectification and disordered eating in young women. Computer Human Behavior 79, 68-74. https://doi.org/10.1016/j.chb.2017.10.027

Delič, 1., Novak, P., Kovačič, J., \& Avsec, A. (2011). Self-reported Emotional and Social Intelligence and Empathy as Distinctive Predictors of Narcissism. Psychological Topics. 20, 3, 477-488.

Dong, Q., Koper, R J., \& Collaço, C. M. (2008). Social Intelligence, Self-esteem, and Intercultural Communication Sensitivity. Intercultural Communication Studies XVII, 162172.

Faraon, M., \& Kaipainen, M. (2014). Much more to it: The relation between Facebook usage and self-esteem.

Forzi, M., \& Not, E. (2003). Correlati dell'autostima in relazione ad età e sesso. Bollettino di Psicologia Applicata, 241, 27-36.

Gini, G., \& Iotti, G. (2008). Una misura multidimensionale dell'intelligenza sociale: validazione preliminare della versione italiana della Troms $\varnothing$ Social Intelligence Scale. Giornale italiano di psicologia, 35 (3), 665-677.

Hahn, C., \& Kim, D. J. (2014). Is there a shared neurobiology between aggression and Internet addiction disorder? Journal of Behavioral Addictions, 3, 12-20. doi: 10.1556/JBA.3.2014.1.2

Kim, E., Koh E. (2018). Avoidant attachment and smartphone addiction in college students: The mediating effects of anxiety and self-esteem. Computers in Human Behavior 84, 264271. 
Kim, H.H. \& Davis, K.E. (2009). Toward a comprehensive theory of problematic Internet use: Evaluating the role of self-esteem, anxiety, flow, and the self-rated importance of Internet activities. Computers in Human Behavior, 25, 490-500.

Lin, M. P., You, J., Ren, Y., Wu, J. Y. W., Hu, W. H., Yen, C. F., \& Zhang, X (2017). Prevalence of Nonsuicidal Self-injury and its Risk and Frotective factors among Adolescents in Taiwan. Psychiatry Research, 255, 119-127. doi: 10.1016/j.psychres.2017.05.028

Lin, M. P., You, J., Ren, Y., Wu, J. Y. W., Hu, W. H., Yen, C. F., \& Zhang, X (2017). Prevalence of nonsuicidal self-injury and its risk and protective factors among adolescents in Taiwan. Psychiatry Research, 255, 119-127. doi: 10.1016/j.psychres.2017.05.028

Maltese, A., Alesi, M., \& Alù, A. G. M. (2012). Self-esteem, defensive strategies and social intelligence in the adolescence. Procedia-Social and Behavioral Sciences 69, 2054-2060

Meerkerk, G. J., van den Eijnden, R. J. J. M., Franken, I. H. A., \& Garretsen, H. F. L. (2010). Is compulsive internet use related to sensitivity to reward and punishment, and impulsivity? Computers in Human Behavior, 26(4), 729-735.

Meijs, N., Cillessen, A. H. N., Scholte, R. H. J., Segers, E., \& Spijkerman, R. (2010). Social intelligence and academic achievement as predictors of adolescent popularity. Journal of Youth and Adolescence, 39, 62-72.

Mellor, D., Fuller-Tyszkiewicz, M., McCabe, M.P. \& Ricciardelli, L.A. (2010). Body image and self-esteem across age and gender: a short-term longitudinal study. Sex Roles, 63, 672681.

Niemz, K., Griffiths, M. \& Banyard, P. (2005). Prevalance of Pathological Internet Use among University Students and Correlations with Self- Esteem, The General Health Questionnaire (GHQ) and Disinhibition. CyberPsychology \& Behavior, 8, 562-570.

Orth, U., Trzesniewski, K. H., \& Robins, R. W. (2010). Self-esteem development from young adulthood to old age: A cohort-sequential longitudinal study. Journal of Personality and Social Psychology, 98, 645-658. http://dx.doi.org/10.1037/a0018769

Perrin, A. (2015). Social Networking Usage: 2005-2015. Pew Research Center.

Rhodewalt, F., \& Vohs, K. D. (2005). Defensive strategies, motivation, and the self: A selfregulatory process view. In A. J. Elliot \& C. S. Dweck (Eds.). Handbook of competence and motivation (pp. 548- 565). New York, NY: The Guilford Press.

Robins, R. W., Trzesniewski, K. H., Tracy, J. L., Gosling, S. D., \& Potter, J. (2002). Global self-esteem across the life span. Psychology and Aging, 17, 423-434. http://dx.doi.org/10.1037/0882-7974.17.3.423

Shaw, B. A., Liang, J., \& Krause, N. (2010). Age and race differences in the trajectories of self-esteem. Psychology and Aging, 25, 84 -94. http:// dx.doi.org/10.1037/a0018242 


\section{SOCIAL SCIENCE, HUMANITIES \& EDUCATION}

6 - 8 MARCH 2020

BUDAPEST, HUNGARY

Silvera, D., Martinussen, M., \& Dahl, T. I. (2001). The Troms $\varnothing$ Social Intelligence Scale, a self- report measure of social intelligence. Scandinavian Journal of Psychology. 42, 4. https://doi.org/10.1111/1467-9450.00242

Trzesniewski, K. H., Donnellan, M. B., \& Robins, R. W. (2003). Stability of self-esteem across the life span. Journal of Personality and Social Psychology, 84, 205-220.

Twenge, J. M., \& Campbell, W. K. (2001). Age and birth cohort differences in self-esteem: A cross-temporal meta-analysis. Personality and Social Psychology Review, 5, 321-344. http://dx.doi.org/10.1207/S15327957PSPR0504_3

Verduyn, P., Ybarra, O., Re'sibois, M., Jonides, J., \& Kross, E. (2017). Do Social Network Sites Enhance or Undermine Subjective Well-Being? A Critical Review. Social Issues and Policy Review, Vol. 11, No. 1, pp. 274--302

Wang, E. S., \& Wang, M. C. (2013). Social support and social interaction ties on Internet addiction: Integrating online and offline contexts. Cyberpsychology, Behavior and Social Networking, 16, 843-849. doi: 10.1089/cyber.2012.0557

Wartberg, L., Kriston, L., Bröning, S., Kegel, K., \& Thomasius, R. (2017). Adolescent problematic Internet use: Is a parental rating suitable to estimate prevalence and identify familial correlates? Computers in Human Behavior, 67, 233-239. doi:10.1016/j.chb.2016.10.029

Wegmann, E., \& Brand, M. (2016). Internet-Communication Disorder: It's a Matter of Social Aspects, Coping, and Internet-Use Expectancies. Frontiers in Psychology, 7.doi:10.3389/fpsyg.2016.01747

White, S.C., \& Blackmore C. (2015). Cultures of Wellbeing: Method, Place, Policy, Palgrave. Macmillan, Basingstoke

Wiederhold, B.K \& Wiederhold, M.D. (2004). The future of Cybertherapy: Improved options with advanced Technologies. (Eds: G.Riva et al). Cybertherapy pp.263. IOS Press.

$\mathrm{Xu}, \mathrm{Q}$., and Mocarski, R. (2014). A cross-cultural comparison of domestic American and international Chinese students' social media usage. Journal of International Students, 4(4), 374-388.

Zaccaro, S. J., Gilbert, J. A., Thor, K. K., \& Mumford, M. D. (1991). Leadership and social intelligence: Linking social perspectiveness and behavioral flexibility to leader effectiveness. Leadership Quarterly, 2, 317-342.

https://www.statista.com/statistics/247938/number-of-social-network-users-in-indonesia/ 